\title{
Health Care Law
}

\author{
Edited by Linda Delany
}

\section{Introduction}

Occupational health services have until now come under little scrutiny in Health Care Law. Access in the UK is patchy and employees often distrust occupational health professionals, regarding them as spies for the employer and ignoring their expertise in work-related illhealth and working environment problems. Nevertheless, recent attempts ${ }^{1}$ to outlaw disability discrimination in employment have drawn attention to the need for accurate assessment of skills and capabilities and for advice on accommodating disability in the workplace. It thus seemed timely to take a look at legal aspects of occupational health provision, particularly in connection with pre-employment screening by employers.

More familiar concerns are raised by our Health Care in the Courts report which tackles the legal problems which beset very premature births. The extent to which the courts have abdicated their powers of calling doctors to account in this sphere has arguably undermined the interests of parents and children, while leaving many doctors with a heavy responsibility which they would sooner not shoulder.

The lack of uniform policies across the country, whether on access to occupational health expertise or on the treatment of very premature babies, worries health care consu-

Correspondence to: Linda Delany, Manchester Metropolitan University, School of Law, Elizabeth Gaskell Site, Hathersage Road, Manchester M13 0JA, UK. mers, raises false expectations and provokes resentment when those expectations are disappointed. The case for national guidelines and strategies deserves to be taken seriously by both the courts and Government.

\section{Reference}

1. In the Disability Discrimination Act 1995.

\section{Occupational Health Services: The Legal Case For Expansion}

\section{Introduction}

Employee access to occupational health expertise is a privilege rather than a right in the United Kingdom. UK legislation aimed at securing health and safety at work is both extensive and detailed but it does not impose an enforceable legal obligation on either employers or the Government to provide occupational health services to the workforce. As a result, access to occupational health professionals depends on employers' attitudes and remains patchy. One consequence of this fragmented approach has been the neglect of a thorough and comprehensive analysis of the functional requirements of different types of work and of 
appropriate methods for assessing the capabilities of job applicants. This is particularly harmful for candidates with disabilities who are wrongly suspected of lacking the capacity to carry out essential (if unspecified or insufficiently analysed) employment tasks.

\section{The Legal Obligations of Employers}

The Health and Safety at Work Act 1974 obliges employers to ensure the health and safety of their employees so far as is reasonably practicable. Despite the plethora of more specific statutory duties which flesh out this requirement, employers in general are not compelled to provide access to qualified medical or nursing staff other than trained 'first-aiders'. ${ }^{2}$ Medical examinations and/or supervision must be available for employees only if their work involves underwater diving, ${ }^{3}$ ionising radiation processes, ${ }^{4}$ contact with lead, ${ }^{6}$ asbestos ${ }^{6}$ or other substances hazardous to health. ${ }^{7}$ The seemingly comprehensive requirements of the Management of Health and Safety at Work Regulations $1992^{8}$ that 'employees are provided with such health surveillance as is appropriate having regard to the risks to their health and safety' as assessed by their employers must be read subject to the provisions of the Approved Code of Practice which accompanies the Regulations and envisages a context in which:

1. 'an adverse health condition' is related to the work in question;

2. there are proven techniques for detecting the condition;

3. there is a reasonable likelihood that the condition will occur; and

4. surveillance is likely to offer protection against the condition to employees at risk. ${ }^{9}$

Employers thus have scope to reach the view that the employment they offer falls outside the above conditions, so that there is no need to offer health surveillance to the workforce.

The 1992 Regulations were intended to implement European Community law, and in particular, Directive 89/391/EEC of 12 June 1989 (the so-called EC Framework Directive) calling for, among other national law measures, health care surveillance which is either appropriate to the risks incurred by workers, or has been requested by the latter. The Directive in turn had been inspired by the requirement of Article 118A of the Treaty of Rome that 'member states should pay particular attention to encouraging improvements, especially in the working environment, as regards the health and safety of workers, and shall set as their objective the harmonisation of conditions in this area, while maintaining the improvements made'.

Other international initiatives in promoting occupational health services, have, not surprisingly, been generated by the International Labour Organisation. Founded in 1919 as a forum for the exchange of views between employer and worker organisations, the ILO aims to raise standards of protection for workers. Most countries are members. In June 1985, the ILO adopted Convention No. 161. Governments who become signatories to the Convention, must formulate, implement and keep under review a coherent national policy on occupational health services and must develop such services for all workers who would benefit from them. Significantly, the Convention regards the adaptation of work to the capabilities of workers in the light of their state of physical and mental health' as a key function of occupational health services. The UK Government has not so far adopted the Convention.

\section{UK Reluctance to Promote Occupational Health Services}

The development of occupational health services never enjoyed unequivocal state support in the United Kingdom. ${ }^{10}$ The Health and Safety Commission despite its responsibilities for proposing new law and initiatives appears to lack resolve in relation to the promotion of occupational health. Although its 1977 discussion document Occupational Health Services: The Way Ahead ${ }^{11}$ acknowledged the problems of providing services to employees of small undertakings and explored ways of promoting cooperation between employers, little change was effected. The Health and Safety Executive, responsible for the enforcement of health and safety law, has never permitted access by individual employees to its Employment Medical Advisory Service, described as 'a natural vehicle by which the 
Government could properly implement the 1989

EC Framework Directive on the provision of accessible, multi-disciplinary preventative occupational health services'. ${ }^{12}$

In 1983 a Parliamentary Select Committee, while recognising the benefits of occupational health services and the prevailing lack of access to such services in smaller firms, concluded against imposing a legal duty to provide access to occupational health. ${ }^{13}$ The Committee considered that the Employment Medical Advisory Service should formulate and monitor the implementation of a non-statutory Code of Practice. Tax incentives could be conferred on firms which observed the Code, and insurers might be persuaded to lower their premiums on policies issued to such employers. GPs should be encouraged to extend their occupational health work and occupational health nurses should be the gate-keepers to further professional help. The Government's response in 1984 welcomed the emphasis on voluntary compliance, doubted whether GPs should become involved, and resolved not to use public funds to provide occupational health services. ${ }^{14}$

Research published in 1993, conducted among 820 private sector firms and 100 public sector organisations, discovered that only $34 \%$ of employees worked in undertakings which employed a doctor, either full or part-time. ${ }^{15}$

\section{The Need for Access to Occupational Health Expertise}

Of the many benefits conferred by access to occupational health expertise, those for job applicants with disabilities have special significance. In general, occupational health provision improves working conditions and health care for employees. For people with disabilities, however, it may well make the difference between securing work at all and staying jobless. This is because employers often equate a disability with inability to work.

There is ample evidence that employers discriminate unreasonably on the basis of information about disability. A good example is provided by a study commissioned by the Spastics Society (now renamed Scope). ${ }^{16}$ Two very similar job applications, only one of which, however, disclosed a non-material disability, were sent out in respect of the same vacancies. Of the 94 employers who showed an interest in at least one of the 'applicants', 37 rejected the disabled one, and only 6 the able-bodied one.

Health screening of prospective employees, whether by clinical examination or merely by exacting health declarations or answers to questionnaires, affords employers a perfect opportunity to discriminate on the basis of disability and has become more common in recent years. The potential for prejudice is much diminished, however, if standards of good practice formulated more than ten years ago $^{17}$ are carefully adhered to:

- no questions about health or disabilities should be included on job application forms;

- separate health declaration forms should be utilised and should be inspected only after the provisional appointment of candidates, and then only by medically qualified people;

- only those medically qualified to do so should be allowed to recommend the rejection of a candidate on health grounds.

Furthermore, any medical vetting of job applicants should only take place 'on the basis of carefully defined criteria relating specifically to the job in question'. ${ }^{18}$ Although employers may feel that they themselves should specify these criteria, research has shown that they are apt to draw their job requirements too tightly. ${ }^{29}$ It has become apparent that what is needed is a process devoid of prejudice and 'capable of placing people accurately within jobs which will not compromise their health or lead to added risk to themselves or others'. ${ }^{20}$ Unfortunately, the UK has no national database which lists the vital skills and health requirements for occupations, nor is there general acceptance of any one method for assessing the potential of job-seekers. Several systems have been devised, however, in England and elsewhere, for matching people to jobs, and it would thus be possible to put together a nationally recognised job placement framework.

The occupational health expertise required to put in place and keep under review a national system for matching people with disabilities or 
health problems to jobs, and to support good individual health screening, needs to be fostered, yet, as was shown above, has hardly been encouraged to develop. This is particularly unfortunate now that the 1995 Disability Discrimination Act has focused attention on the need for good practice in the recruitment of employees. The Act does not prohibit preemployment health checks and questionnaires but does expect employers not to use them in discriminatory ways. Disabled applicants should not be prematurely excluded from the selection process as the key issue is capacity to do the work on offer. Information elicited as a result of health screening should lead to individualised enquiries, and may also be used to work out the adjustments which an employer must within reason make in order to accommodate disabled new employees. ${ }^{21}$ Admittedly, the Act exempts employers of fewer than 20 employees from its provisions. As a result, however, just those (small) businesses which have least access to occupational health expertise, can practise discrimination with impunity.

\section{Conclusion}

Occupational health services underpin good employment practice, and should be extended. Small firms cannot be expected to offer an inhouse occupational health service, but they should use the services of occupational health professionals and could become members of group services providing facilities on a shared basis. At national level, the Health and Safety Commission should address the need for a comprehensive analysis of health and skill requirements pertinent to jobs. Such an analysis would be invaluable to firms committed to antidiscrimination policies.

\section{References}

2. Health and Safety (First Aid) Regulations 1981. SI $1981 / 917$.
3. Diving Operations at Work Regulations 1981. SI $1981 / 399$.

4. Ionising Radiations Regulations 1985. SI 1985/ 1333.

5. Control of Lead at Work Regulations 1980. SI 1980/1248.

6. Control of Asbestos at Work Regulations 1987. SI $1987 / 2115$.

7. As defined in the Control of Substances Hazardous to Health (COSHH) Regulations 1988. SI $1988 / 1657$.

8. SI $1992 / 2051$.

9. Approved Code of Practice, para. 30.

10. For a short history of occupational health services provision, see Kloss, D. (1994) Occupational Health Law, Blackwell Scientific Publications, Oxford, Chapter 1.

11. Health and Safety Commission (1977). Occupational Health Services: The Way Ahead, HMSO, London.

12. Hughes, M. (1997). Working towards a national $\mathrm{OH}$ service. Occupational Health 49, 138-140.

13. House of Lords Select Committee on Science and Technology (1983). Occupational Health and Hygiene Services (Gregson Report) HLP 28, HMSO, London.

14. House of Lords Select Committee on Science and Technology (1984). Occupational Health and Hygiene Seroices: The Government Response, HLP 289, HMSO, London.

15. Bunt, K. (1993). Occupational Health Provision at Work, HMSO, London.

16. Graham, P., Jordan, J. and Lamb, B. (1990). An Equal Chance?-Or No Chance?, The Spastics Society, London.

17. See Floyd, M. and Espir, M. L. E. (1986). Assessment of medical fitness for employment: the case for a code of practice. The Lancet II, 207-209.

18. Health and Safety Executive (1982). Pre-employment Health Screening (Guidance Note MS 20), Health and Safety Executive, London.

19. Morrell, J. (1990). The Employment of People with Disabilities. Research into the Policies and Practices of Employers (Research Paper No. 77), Department of Employment, London.

20. Chaplin, J., Edwards, F. and Floyd, M. (1992). Towards a Framework for Appropriate and Safe Job Placement, City University Rehabilitation Resource Centre, London.

21. See sections 4-6 of the Disability Discrimination Act 1995 and the provisions of Para. 5 of Department for Education and Employment (1996). Code of Practice for the Elimination of Discrimination in the Field of Employment against Disabled Persons or Persons who have had a Disability, HMSO, London. 


\section{Health Care in the Courts}

\section{The Result of the Fatal Accident Inquiry at Kilmarnock Sheriff Court into the Death of Rebecca Cassidy. 26 June 1997}

Rebecca Cassidy was born on 7 September 1996 at Ayrshire Central Hospital in Scotland. She weighed only 20 ounces and gestation was variously estimated to have been 23,24 or 25 weeks, with the Hospital putting forward the lowest estimate and Rebecca's mother, Kirsty Cassidy, the highest. According to Kirsty Cassidy, Rebecca could breathe and move and should have been offered intensive care. Rebecca's paediatrician, Dr Faisal Al-Zidgali disagreed: he feared that the baby was at high risk of brain damage and other disabilities and considered her to be gasping rather than breathing and her movements to be muscle spasms. His decision that the baby was 'non-viable' and should peacefully be allowed to die was supported by other medical staff including Mrs Cassidy's midwife.

Rebecca died not long after her birth and the hospital initially treated the episode as a spontaneous abortion at 23 weeks gestation. Only when Mrs Cassidy complained was a death certificate issued.

The inquiry into Rebecca's death had to determine whether the Ayrshire Central Hospital had taken all reasonable measures to prevent Rebecca's death. Sheriff Principal Robert Hay who presided, heard evidence from Mrs Cassidy that while she had been warned her baby might die, no-one had told her that no steps would be taken to save the baby. She had expected the baby to be placed in intensive care and the adoption of a 'wait and see' approach involving consultation with her and her husband about Rebecca's fate. Doctors, she claimed, should not have a monopoly on life-or-death decisions regarding babies. If parents wished their baby to have intensive care, however poor the prognosis, doctors should act on that wish. It was the parents who created the child in the first place and the law should be changed to take account of that fact. Dr Al-Zidgali told the Sheriff that it was futile and foolish to treat a baby whose prematurity made her nonviable. He claimed that had he been asked to try everything possible to save the baby, he would have called for a second opinion from a consultant, but that no such request had been made.

The Sheriff, having offered his sympathy to $\mathrm{Mr}$ and Mrs Cassidy found that Dr Al-Zidgali had taken a reasonable clinical decision in the baby's best interests and was entitled to treat Rebecca's welfare as paramount. He accordingly ruled that Ayrshire Central Hospital had taken all reasonable steps to prevent the baby's death.

\section{Comment}

As Mrs Cassidy herself recognised, existing law was never likely to support her claim that parents should have the final say in their child's treatment. The British Medical Association may at one time have thought that medical decisions for children ultimately lay with their parents ${ }^{22}$ but the legal position is much more complex than this. A person with parental responsibility for a child is entitled on behalf of the infant to consent to or reject treatment if the parent considers that the best interests of the child so require'.23 This implies that a parent, acting on his or her perception of the child's best interests, may respond, either positively or negatively, to medical recommendations, but has no power in law to demand a particular course of treatment. That this view is correct was confirmed by the Court of Appeal in the case of $\operatorname{Re} J$ ( $A$ Minor) [1992] 2 FLR 165. J had suffered accidental injury to the head at the age of one month and this had left him profoundly physically and mentally handicapped. At 18 months, his life expectancy was considered low and he was not expected to develop beyond his then extremely limited level of functioning. He suffered from cerebral palsy, epilepsy and cortical blindness and was cared for by foster-parents appointed by the local authority which shared parental responsibility for J with his divorced parents. J was fed mainly by naso-gastric tube and suffered fits and breathing problems which might kill him. His consultant paediatrician reached the conclusion, supported by two other consultant paediatricians, that if J suffered a life-threatening episode it would be cruel to place him on a ventilator, although resuscitation with suction, physiotherapy and antibiotics would be offered to him. J's 
mother, however, disagreed on the issue of positive pressure ventilation and wanted intensive measures to be applied. To resolve the conflict, the local authority had recourse to the inherent jurisdiction of the court over children, and sought an order requiring the health authority to continue to provide all available treatment to $\mathrm{J}$, including intensive resuscitation'.

Once courts act in the exercise of their inherent jurisdiction, they, rather than those with parental responsibility for the child, have proxy powers on behalf of the child. Even so, the Court of Appeal in $R e$ J considered that it would be an abuse of power to require a doctor to embark on a course of treatment which is not, according to that doctor's clinical judgement, in the patient's best interests. That others, including the court, disagreed with the doctor's judgement was irrelevant. If a court could order a treatment for a child, then a conscientious doctor who disagreed with that treatment might find him or herself in the untenable position of having to choose between contempt of court proceedings and the best interests of the child.

Lord Donaldson who delivered the leading judgement, based it on his analysis, in an earlier case, also known as $\operatorname{Re} J^{24}$ of the child-parentdoctor-court relationship. There he had said that no-one could dictate the treatment a child should have. Doctors could recommend treatment $\mathrm{A}$ rather than treatment $\mathrm{B}$. They could also refuse to adopt treatment $C$ as a treatment which they could not conscientiously administer. The court or the parents could refuse to consent to treatments $\mathrm{A}$ or $\mathrm{B}$ or both but could not demand treatment $C$. 'The inevitable and desirable result' was a measure of agreement between court, doctors and parents.

Although the 1992 Re J dilemma and the sad circumstances of Rebecca Cassidy's death show that agreement between doctors and parents is far from inevitable, one may in general agree with the Court of Appeal that it would be unwise to allow parents or judges to dictate treatments to doctors. However, to rely too heavily on doctors' perceptions of what is medically in a child's best interests undermines the protection which courts, and indeed parents, should be able to offer children. When parents endanger children, by, for example, rejecting emergency treatment, doctors may intervene to do what they consider to be essential in the children's best interests; ${ }^{25}$ why then should not the courts, at the instigation of the parents and on the basis of expert evidence, also be able to insist on vital treatment when doctors seem unwilling to commence it? The need for court orders of this kind is unlikely to arise frequently, but to prohibit such orders altogether weakens medical accountability too much. Decisions about suitability for neonatal intensive care are based on judgements about quality of life and social worth as well as medical insight and not just doctors should be involved in them. As Lord Donaldson himself recognised in the $1990 \mathrm{Re} J$ case,

Doctors nowadays recognise that their function is not a limited technical one of repairing or servicing a body. They are treating people in a real life context. This at once enhances the contribution which the court or parents can make towards reaching the best possible decision in all the circumstances. ${ }^{26}$

The Re J 1992 refusal to ever dictate to doctors seemed out of line with this approach and a retrograde step.

It is, however, true that for very premature babies, Lord Donaldson's 'real life context' may be unpromising. The complex and interrelated clinical problems which beset such babies may lead to significant disability in later life for survivors. The incidence of cerebral palsy, cognitive and learning disorders and visual and hearing impairments (the latter often leading to a delay in speech development) is much higher in children born preterm than in those born at term. ${ }^{27}$ The severity of these disorders varies widely and is hard to predict but at least some children will throughout their life remain completely dependent on other people.

As has been vividly illustrated, ${ }^{28}$ some paediatricians in the UK are much more willing than others to treat very premature babies aggressively. Both full scale intensive care and less invasive measures can be justified and have their medical supporters, so the courts, were they asked to review a treatment decision, would be loath to declare it unlawful. However, as only the survival in good health, but not the death or disability of extremely young babies continues to 
attract publicity, many parents do not appreciate, first, that not all maternity hospitals approve of aggressive treatment, and secondly, that there may be good reasons for refusing intensive care. The hospital decision may then seem arbitrary and callous.

Where the delivery is expected to be preterm by several weeks the implications of this for the baby and parents should of course be discussed so that the courses of action appropriate to different potential outcomes of the birth can be agreed. However, time for such consultation will often not be available until after the birth. Either way, only when the baby can be examined will doctors really be in a position to judge what is in his or her best interests. Unfortunately, they have few legal guidelines to help with this. Regular readers may recall last year's application to the High Court for guidance as to when braindamaged babies may be allowed to die. ${ }^{29}$ The Court insisted that each case should be judged in the light of its individual circumstances. This leaves paediatricians to apply the vague criteria referred to by the Court of Appeal in the much earlier case of $\operatorname{Re} B:{ }^{30}$ will the life of the child be demonstrably so awful, because of pain and suffering, that it should end or is the quality of life so imponderable that permitting death would be wrong? ${ }^{31}$

Some health authorities consider that scarcity of resources is a compelling argument for refusing intensive treatment for extremely premature babies. If the refusal is consistently linked to low birth weight or duration of gestation (so that it can be shown that even with treatment, babies would rarely survive) the policy would be lawful. The courts, having no knowledge of competing claims to resources, whether human or material, have in any case been reluctant to criticise allocation decisions by health authorities. ${ }^{32}$

A final issue raised by the inquiry into Rebecca Cassidy's death is the assessment of the length of gestation. It is important legally because, as discussed in the last paragraph, it may be used to justify a blanket ban on aggressive treatment and because under the Still-Birth (Definition) Act 1992, the threshold gestational age which separates still-birth from a spontaneous abortion is 24 weeks. ${ }^{33}$ However, as the Cassidy case itself illustrates, calculating gestational age is proble- matic because of fixing the starting point. In the $\mathrm{UK}$, the medical profession deems pregnancy to start on the first day of the woman's last period, without regard for an exact date of conception (which may be more than two weeks later in a normal menstrual cycle) or for the likely date of implantation. The law itself provides no guidance, so it is not surprising that there may be a genuine conflict between doctors and parents as to gestational age. Having said that, the medical approach to the calculation should normally provide an older age than the real one.

\section{References}

22. See anon. (1981). Medical news. British Medical Journal 283, 567.

23. Gillick $v$ West Norfolk and Wisbech Area Health Authority [1985] 3 All ER 402, 432 per Lord Templeman.

24. [1990] 3 All ER 930.

25. See Gillick $v$ West Norfolk and Wisbech Area Health Authority 19853 All ER 402, 432 per Lord Templeman.

26. Re J (a minor) (wardship: medical treatment) [1990] 3 All ER 930, 934.

27. Griffin, J. (1993). Born Too Soon, Office of Health Economics, London.

28. In the BBC 1 television programme Panorama: Salvaging Babies broadcast on 18 July 1994.

29. Re C. April 1996. Health Care Analysis 4, 340-342.

30. [1990] 3 All ER 927. The case was decided in August 1981 but not reported in the All England Law Reports until 1990.

31. per Templeman LJ. at 929.

32. See Lord Donaldson in $\operatorname{Re} J$ [1990] 3 All ER 930 and in $\operatorname{Re} J$ [1992] 2 FLR 165.

33. It also has legal relevance in the context of elective abortion.

\section{News Brief}

\section{Physician Assisted Suicide in the United States}

In a unanimous judgement, the United States Supreme Court, on 26 June 1997, refused terminally ill patients the right to doctor-assisted suicide. The Court, citing 700 years of AngloAmerican laws discouraging suicide, ruled that a patient has no constitutional right to die with the help of a doctor. The judges did, however, recognise the right of patients to refuse treatment, even if such refusal hastened death. 


\section{Clawing Back Compensation}

An English health authority whose negligence substantially contributed to injuries sustained by a baby at birth is looking into the possibility of claiming back part of the compensation it paid now that the little girl has unexpectedly died at the age of 9 . The authority considers that it has a legal, moral and financial duty to make its unprecedented attempt to claw back some of the money.

\section{Challenges to the Tobacco Industry}

Hot on the heels of the American settlement under which cigarette companies have agreed to pay billions of dollars towards the care of sick smokers in return for immunity from future lawsuits, a group of NHS authorities in England are seeking to achieve a similar deal to help with the cost of treating English patients suffering from smoking-related illness.

\section{Surrogacy Review}

The financial aspects of surrogacy in Britain are to be reviewed by a Government appointed team headed by Professor Margaret Brazier of Manchester University. Commercial surrogacy in the United Kingdom is not illegal if payments are made to the surrogate mother by the commissioning parent, but payments to agencies or clinics are not permitted. The outcome has been a lack of regulation in a sphere which might benefit from some legal control.

\section{Germany's New Organ Transplant Law}

A new law, which for the first time recognises that brain stem death is death for legal purposes, has been enacted by the German parliament. The measure also allows proxy consent to organ removal by relatives of the donor, so long as they believe that they are carrying out the donor's wishes. 